\title{
ALCANCE
}

\section{CENTRALIDADE E DENSIDADE EM UMA REDE DE LOGÍSTICA REVERSA DE EMBALAGENS DE DEFENSIVOS AGRÍCOLAS}

CENTRALITY AND DENSITY IN A REVERSE LOGISTICS PACKAGING NETWORK FOR PESTICIDES

CENTRALIDAD Y DENSIDAD EN UNA RED DE LOGÍSTICA REVERSA DE ENVASES DE DEFENSIVOS AGRÍCOLAS

CAROLINE CORADASSI ALMEIDA SANTOS

Doutoranda

Universidade Estadual do Centro Oeste - Brasil

ORCID: 0000-0001-9192-8127

carol_coradassi@hotmail.com

MARCOS DE CASTRO

Doutor

Universidade Estadual do Centro Oeste - Brasil

ORCID: 0000-0002-4837-0399

marcosdecastroms@yahoo.com.br

LUCIANO FERREIRA DE LIMA

Doutor

Universidade Estadual do Centro Oeste - Brasil

ORCID: 0000-0001-9495-0098

prof.lucianolima@yahoo.com

INDEXED BY

Submetido em: 07/06/2018

"'redalyc.org

Aprovado em: 28/04/2019

Doi: 10.14210.alcance.v26n2(mai/ago).p212-228

\section{LCENÇA CC BY:}

Artigo distribuído

sob os termos

Creative Commons,

permite uso e

distribuição irrestrita

em qualquer meio

desde que $o$ autor

credite a fonte

original. 


\section{RESUMO}

O artigo buscou compreender a relação entre os atores e a formação de rede na cadeia reversa das embalagens de defensivos agrícolas na região centro-sul do Estado do Paraná. Por se tratar de um estudo de caso, tomou como referência a Associação dos Distribuidores de Defensivos Agrícolas do Centro-Sul (ADDCS), que é corresponsável pela captação de embalagens e pela destinação correta, juntamente com o Instituto Nacional de Processamento de Embalagens Vazias (INPEV). A escolha metodológica para a realização do estudo possui uma abordagem qualitativa com suporte quantitativo. Assim, para a coleta de dados em campo foram realizadas entrevistas estruturadas com base em um roteiro de avaliação sociométrica e entrevistas semiestruturadas com os principais atores relacionados à organização foco do estudo. Os resultados apontaram que há uma relação interorganizacional, mas os resultados apontam ainda uma rede com características difusas, ou seja, atores com pouco contato podem ser fatores que ainda venham a restringir o alcance de melhores resultados, sendo que muitas vezes as ações dos agentes são induzidas por possiveis sanções que possam sofrer em virtude da lei.

Palavras-chave: Redes; Análise e estrutura; Logística reversa.

\section{ABSTRACT}

This article aims to understand the relationship between the actors and network formation in the reverse chain of agricultural pesticide packaging in the Central-South region of the State of Paraná. It is in the form of a case study of the Association of Agricultural Pesticide Distributors of the Central-South Region (Associação dos Distribuidores de Defensivos Agrícolas do Centro-Sul - ADDCS), which is responsible for the collection and safe disposal of packaging, together with the National Institute for Empty Packaging Processing (Instituto Nacional de Processamento de Embalagens Vazias - INPEV). In terms of methodology, the qualitative approach was used for this study, supported by the quantitative approach. Data were collected in the field using structured interviews, based on a roadmap of sociometric evaluation, and semi-structured interviews with key actors related to the organization that is the focus of the study. The results showed that there is an interorganizational relationship, but the results still point to a network with diffuse characteristics, i.e. actors with little contact may be factors that still restrict the achievement of better results. Often, the actions of the agents are prompted by possible legal sanctions that might be imposed on them.

Keywords: Networks; Analysis and structure; Reverse logistic.

\section{RESUMEN}

Este artículo propone, como eje central, el análisis de propiedades y estructuras de redes. Para ello, el objetivo general buscó comprender la relación entre los actores y la formación de red en la cadena reversa de los envases de defensivos agrícolas, en la región Centro-Sur del Estado Paraná. Por tratarse de un estudio de caso, tomó como referencia la Asociación de Distribuidores de Defensivos Agrícolas del Centro-Sur (ADDCS), que es corresponsable por la captación de envases y destino correcto, junto con el Instituto Nacional de Procesamiento de envases vacíos (INPEV). La elección metodológica para la realización del estudio tiene un enfoque cualitativo con soporte cuantitativo. Así, para la recolección de datos en campo se realizaron entrevistas estructuradas sobre la base de un itinerario de evaluación sociométrica, y entrevistas semiestructuradas con principales actores relacionados a la organización foco del estudio. Los resultados apuntaron que hay una relación interorganizacional, pero los resultados apuntan aún una red con características difusas, o sea, algunos actores con poco contacto, pueden ser factores que aún vienen a restringir el alcance de mejores resultados, siendo que muchas veces las acciones de los "los agentes son inducidos por posibles sanciones que puedan sufrir en virtud de la ley.

Palabras clave: Redes; Análisis y estructura; Logística inversa. 


\section{INTRODUÇÃO}

Considera-se rede a interligação das organizações, vistas como atores ou agentes, um ponto ou nó na formação de elos (Nohria, 1992). A análise da estrutura e da formação de redes representa as relações estabelecidas entre os atores pertencentes, bem como as formas de conectividade entre os diferentes atores que buscam, por meio desses relacionamentos, a excelência em seus processos (Balestrin, Vershoore, \& Reyes Jr. 2010). Logo, nota-se que o objetivo principal da análise da estrutura de rede consiste em compreender como e quanto os diferentes agentes se relacionam, de que forma e com que intuito.

Nesse sentido, evidencia-se a formação de rede na relação de vários atores ou diferentes agentes envolvidos em um processo, seguindo a característica inicial de envolvimento de aspectos internos com os externos não exclusivamente dominantes por uma empresa. Assim, observa-se que a relação em redes propõe, de certa forma, aproveitar características do ambiente externo, presentes nas empresas concorrentes e aproximar da própria empresa, a fim de garantir a sobrevivência diante das condições de concorrência (Araújo, 2000).

A estrutura em rede, inicialmente, caracteriza-se pelo poder das organizações no sentido econômico e social, mas se pode definir como um conceito multifacetado, compreendido, por exemplo, por condições de assistência, geográficas, de valores e econômicas. A integração dessas múltiplas facetas forma a estrutura de redes de determinado cluster. Ainda, de acordo com Farina, Silva, Silva Filho, Silveira, Ozaki e Benevides (2013), a estrutura em redes trata-se de um fenômeno multinível, que impacta diretamente as condições dinâmicas de competição e "colaboram na comparação dos efeitos dos vários níveis" (Gnyawali \& Madhavan, 2001, p. 435). Ou seja, Wasserman e Faust (1999, p. 24) demonstram o nível das relações, "isto é, de nível ator, de nível par, e em nível de rede analisa".

Considerando que o conceito de rede visa ao relacionamento de organizações em prol de um objetivo comum (Balestrin et al., 2010) e, ainda, por meio das relações em rede, os impactos estruturais caracterizados representam uma economia organizada, cujos benefícios se estendem a um gerenciamento de informações, de capacidade tecnológica e intelectual (Farina et al., 2013). Tal capacidade, logicamente, tem reflexos diretos sobre os resultados alcançados pelas organizações formadoras de uma rede. Dessa forma, o foco deste estudo está na compreensão do modelo de formação de rede no processo de retorno de embalagens de agrotóxicos na região centro-sul do Paraná.

Esse estudo possui, como base norteadora de pesquisa, o modo como se relacionam os diferentes atores pertencentes à rede, à sua organização, à frequência e à importância de contato, bem como suas ações, aspectos de liderança, além das vantagens e das desvantagens relacionadas a esse processo. Assim, este artigo discute sobre a análise de propriedades e as estruturas de redes. Logo, tem-se 0 objetivo de compreender a estrutura em relação aos aspectos de densidade e centralidade no relacionamento entre os atores da cadeia reversa das embalagens de defensivos agrícolas, considerando que a centralidade caracteriza a posição dos atores na rede e a densidade o número de ligações ou vínculos, ressaltando Tichy, Tushman e Fombrun (1979). Ainda, Freeman (1979) distingue três tipos de centralidade, grau [degree], proximidade [closeness] e intermediação [betweenness].

Sobre os aspectos de estrutura para sua contextualização e definição dos diferentes cenários gerados pelos atores que compõem todo este processo, notavelmente, uma sequência de conceitos e atributos deverão ser analisados. Para tanto, este estudo terá como base a compreensão das propriedades e a estrutura da rede, bem como a identificação dos clusters que integram a estrutura da rede, seu modo de interação e principais ações dos diferentes tipos de atores.

Para a análise, serão considerados os eixos norteadores:

a) A estrutura da rede em relação à centralidade e à densidade;

b) As práticas de gestão estabelecidas a partir da organização em rede;

c) Os resultados alcançados a partir das relações interorganizacionais;

d) As influências e a intensidade de relacionamento.

Dessa forma, posteriormente à introdução do tema, este artigo foi dividido em quatro capítulos. Inicialmente serão discutidos os conceitos sobre o tema abordado, na sequência as metodologias aplicadas neste estudo, em seguida, a constituição da análise dos dados e, por fim, as considerações finais. 


\section{REDES COMO PERSPECTIVA DE ANÁLISE ESTRUTURAL E LOGÍSTICA REVERSA DE EMBALAGENS}

De acordo com Britto (2002), quando se trata da formação de redes, deve-se compreender os principais elementos morfológicos que integram este conceito às redes formadas por nós, posições, ligações e fluxos, ou seja, determinam sua estrutura de relacionamentos. As estruturas organizacionais surgem e são formalizadas a partir de aspectos estruturais e institucionais, que envolvem a produção de técnicas e trocas, sejam de produtos e/ou serviços, controladas e coordenadas, a fim de se garantir a sobrevivência e a continuidade da organização.

Os métodos de ação e os de trabalho das organizações baseiam-se em regras e valores definidos a partir de características da sociedade ou sob o estabelecimento de diretrizes estruturais, as quais trazem o delineamento e a configuração do modo de agir (Contractor, Monge, \& Leonardi, 2011).

Para Britto (2002), os elementos morfológicos que compõem a rede podem ser descritos como: nós, posições, ligações e fluxos. Os nós são representados por agentes ou atores pertencentes à rede. Já as posições representam onde estão localizados estes agentes, o que demonstra a divisão de trabalho. Depois, as ligações que determinam a densidade dos atores da rede, ou seja, a proporção de todos os nós presentes em relação aos possíveis nós da rede. Por fim, os fluxos que revelam os itens da relação de troca, se tangíveis ou intangíveis.

Logo, trata-se de conceitos da chamada análise de redes sociais, que surgiram e foram contextualizadas com base em estudos antropológicos e sociológicos e que, fundamentalmente, corroboram para o estabelecimento dos estudos sobre análise de estruturas de redes e suas relações - interorganizacionais (Araújo, 2000).

Uma das concepções que retratam a influência dos relacionamentos, dentro da rede, demonstra inicialmente a capacidade baseada nos recursos, os quais, necessariamente, não compreendem apenas aspectos internos à organização, mas que podem ser vistos como características pertencentes à rede, sejam informações, tecnologias ou habilidades (Marteleto, 2010). Ainda na relação de rede, ao se tratar recursos, existem quatro argumentos principais que corroboram para o fortalecimento desta perspectiva, em que se destacam condutas, economias externas, taxa de retorno e aquisição, que influenciam o comportamento competitivo dentro da rede e proporcionam o fortalecimento dos laços de relacionamento (Albagli \& Brito, 2003). Masquieto, Sacomano Neto e Giuliani (2011) mencionam as organizações como sistemas abertos que influenciam e são influenciadas pela rede, a qual estão inseridas, seja por relações formais ou informais.

Ainda se tratando da configuração de níveis na rede de relacionamentos, Gnyawali e Madhavan (2001) tratam as propriedades estruturais na formação de redes como sendo centralidade, autonomia estrutural, de equivalência estrutural e densidade da rede. Nesse modelo, os autores ressaltam a condição do fluxo de relação e as diferenças pertinentes à propriedade estrutural, em relação aos níveis em que cada empresa está inserida. Desse modo, o reflexo desse modelo será sobre as ações e o poder de decisão de cada membro da rede, observando de acordo com as características de atuação. Sobre a centralização, por exemplo, percebem-se algumas características críticas no sentido da tomada de decisão.

Gnyawali e Madhavan (2001) tratam o conceito de centralidade como sendo uma posição estratégica, que permite influenciar ou se relacionar com outros agentes dentro da rede, ou seja, quando sua posição dentro da rede permite a relação com outros atores, ressaltando que os principais fatores de influência sobre a capacidade de relacionamentos indicam, primeiramente, a capacidade tecnológica, financeira, econômica e outros recursos que venham a impactar em toda a ação da organização e aqueles relacionados a ela, posteriormente, à capacidade de acesso à informação. Assim, nota-se o quão forte aquele agente é dentro da rede e quantos outros atores são dependentes.

0 agrupamento dessas diferentes empresas se estabelecem em diversas circunstâncias de relacionamento, caracterizados por Oliver (1990) como assimétrico, recíproco, eficiente, estável e legítimo, ou seja, as influências dos modos de relacionamento demonstram o nível e as condições de envolvimento de diferentes empresas.

As relações interorganizacionais também passam por situações de governança e gestão, que são caracterizadas como regras definidoras ou norteadoras, e que permitem certo grau de confiança na relação, além de transmitir a ideia de dinâmica delimitada por regras e condições vinculadas a um poder de liderança, de laços fortes e fracos, ou de cooperação e conflito (Rodrigues, Maccari, e Riscarolli, 2007).

Para Araújo (2000), as relações interorganizacionais possuem duas linhas de pensamento, a condição de custos de transação e a teoria evolucionista das competências. Essas relações são estabelecidas por meio de contratos, os quais têm por finalidade a regulação de ações que desenvolvem as características de confiança nessa relação, e as condições relacionadas aos limites racionais no desenvolvimento de aspectos tecnológicos, que impulsionam as vantagens competitivas. Para tanto, nota-se que as duas linhas de pensamento ora se complementam, ora se 
contradizem, concebendo poder aos quesitos de especialização, oportunismo e racionalidade sob certa condição hierárquica limitada por estruturas de contratos preestabelecidos.

A densidade, que é a variável abordada por essa análise, pode ser entendida como a extensão da interconexão entre os atores. Essa interconexão pode ocorrer por meio de contratos, troca de informações, nível de confiança, cooperação, arranjos entre empresas, entre outros.

Nas redes densas, observam-se três características importantes: facilidade do fluxo de informações e recursos; sistemas fechados de confiança; normas com comportamentos comuns e facilidade na atribuição de sanções (Hanneman \& Riddle, 2005). Nas redes densas e coesas, a interconexão entre as empresas é maior e as informações são mais refinadas. Nas redes difusas, a interconexão é menor, porém ocorre o acesso a informações novas. A variável de análise da posição relacional é a coesão. Coesão é a intensidade dos relacionamentos que podem ser fortes ou fracos (Balestrin $\&$ Vershoore, 2008). As redes densas e difusas diferem-se quanto ao relacionamento com os fornecedores. Nas redes densas e coesas, frequentemente, clientes e fornecedores trabalham em uma mesma região geográfica.

Porém, quando há muita dependência por alguns fornecedores, o comprometimento é maior e a preocupação em desenvolver novos fornecedores para suprir possíveis falhas de fornecimento deve ser considerada (Waichman, 2012). Nas redes difusas, o número de fornecedores é bem maior, o que dificulta e também ameniza a necessidade de desenvolvimento de fornecedores. Nesse caso, a busca de novos fornecedores não é influenciada pelo posicionamento da empresa focal na rede (Marteleto, 2010).

$\mathrm{Na}$ análise de estruturas e propriedades de redes, são observados alguns fatores, por exemplo, quanto à posição dos atores, ao seu poder dentro da rede e à proporção de relações. A característica estrutural de centralidade é subdividida em três outras três medidas: centralidade de grau (degree centrality), a qual demonstra o número de relacionamentos de um ator dentro da rede; centralidade de intermediação (betweenness centrality), refere-se àqueles atores que fazem a intermediação entre outros atores dentro da rede; e centralidade de proximidade (closeness centrality), o relacionamento entre diferentes atores sem intermediários. E densidade é o número de ligações entre os atores (Tichy, Tushman, \& Fombrun, 1979). No entanto, além dos aspectos estruturais, que auxiliam na análise da rede, outro fator a ser discutido para melhor entendimento do caso em estudo são os aspectos de logística reversa.

A logística reversa é vista como o fluxo reverso de produtos já comercializados, ou seja, o qual leva o produto do ponto de consumo ao seu ponto de origem (Goldsby \& Closs, 2000). Os processos de logística reversa contribuem com o meio ambiente e os fatores de sustentabilidade, permitindo que produtos e embalagens sejam recuperados $\mathrm{e}$ reutilizados (Demajorovic, Caires, Gonçalves \& Silva, 2014).

Existem políticas que colaboram com o consumo consciente fortalecendo a adoção de processos de logística reversa. Para indústria produtora de defensivos agrícolas existem leis e normas que obrigam o retorno das embalagens para que sejam recicladas ou incineradas e não fiquem em exposição ao meio ambiente, devido ao grau de risco e à contaminação que pode acarretar para saúde humana, animal e ao ecossistema (Ferri, Chaves, \& Ribeiro, 2015).

Por isso foi criado o INPEV, que possui atuação nacional. No entanto, para ter um controle efetivo dos produtos consumidos e das embalagens que devem retornar para reciclagem ou incineração, foram criadas associações distribuídas em cada Estado e região (Lacerda, 2002). No Estado do Paraná, existem 13 associações, considerando que, para as empresas obterem alvará de funcionamento, comercializarem e distribuírem defensivos agrícolas, precisam associar-se ou realizar individualmente a coleta e a devolução das embalagens para indústria produtora. Por se tratar de atividade complexa que atende a uma série de requisitos, a maior parte dos distribuidores são associados e realizam 0 trabalho de modo conjunto (Demajorovic \& Massote, 2017).

Evidencia-se a existência de uma rede no que tange ao retorno das embalagens em decorrência dos relacionamentos e das trocas em função de um objetivo comum (Ladeira, Maehler e Nascimento, 2012). Diversos atores localizados a nível nacional fazem parte de toda a logística reversa, que inclui indústria produtora, distribuidores, consumidores, agências reguladoras, associações e o INPEV. No entanto este estudo tomou como base a região centrosul do Estado do Paraná.

\section{METODOLOGIA}

A pesquisa realizada possui uma abordagem qualitativa com complemento quantitativo. Embora esse estudo seja mais próximo de metodologia que se aproxima de análise qualitativa, na coleta de dados foram usadas técnicas qualitativas e quantitativas, como forma de consubstanciar, analiticamente, os resultados. Nesse sentido, trata-se de uma pesquisa 
de natureza descritiva e exploratória, com intuito de compreender a formação da rede de logística reversa de embalagens de defensivos agrícolas (Creswell, 2010).

Para tanto, optou-se como método central o estudo de caso, o qual visa investigar variáveis e resultados de uma situação específica, real e contemporânea, por meio da coleta e da análise de dados (Yin, 2015). Tomou-se como referência a ADDCS, por se tratar da unidade de recebimento de embalagens mais próxima, sendo que esta possui trinta empresas associadas. Como destacado anteriormente, a rede é formada por diversos atores, sendo produtores, distribuidores, agências reguladoras, associações e indústrias que são representadas pelo INPEV, e toda a logística reversa faz parte do programa chamado Sistema Campo Limpo.

De modo geral, o sistema campo limpo é gerenciado pelo INPEV, que conta com a participação de mais de 100 indústrias, além de 1,4 milhão de produtores que são consumidores dos produtos e estão registrados nas bases de informações das agências reguladoras e fiscalizadoras, como também 411 unidades de recebimento que fazem 0 encaminhamento para reciclagem e incineração. Ressalta-se que $90 \%$ do material é reciclado e os outros $10 \%$ incinerado, o que minimiza a exploração de petróleo para produção de novas embalagens.

A pesquisa caracteriza-se, também, como exploratória, pois a coleta de dados, inicialmente, aconteceu por meio do estudo e da análise de documentos bibliográficos, os quais são vistos como dados secundários; na sequência, realizouse a coleta de dados primários por meio de entrevistas e questionários (Cooper \& Schindler, 2011).

Por se tratar de um grande contingente de atores, também foram coletados dados por meio de um Questionário de Avaliação Sociométrica (QAS). Este questionário busca compreender os atores mais citados, a frequência de contato, o motivo do contato e a importância dos atores citados por cada um dos respondentes para a efetivação de suas ações em benefício do processo de logística reversa das embalagens. Por fim, elaborou-se a construção de diagramas e matrizes, com base em técnicas matemáticas, por meio de programa informatizado específico, porque permite lançamento de dados coletados e que facilitam a visualização do resultado desta análise, ou seja, a formação de uma rede constituída por diversos atores. Além disso, este artigo é apresentado com características de pesquisa descritiva, pois pretende demonstrar uma representação do conjunto de empresas.

Os dados obtidos, por meio de entrevista estruturada, foram transcritos e foi desenvolvida uma matriz para extração dos dados significativos a esta análise. Para o cálculo das medidas de análise, foram lançados dados da matriz

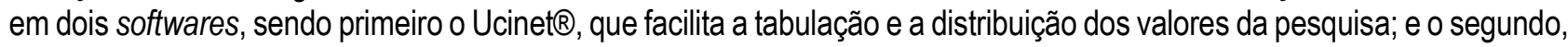
o NetDrawß, que em conjunto com o primeiro, possibilita a visualização da distribuição do sistema de rede e, também, deixa mais evidente a percepção da densidade no grau de centralidade dessa rede.

Foram coletados trinta e seis questionários de avaliação sociométrica no período de outubro e novembro de 2017 , além de cinco entrevistas semiestruturadas. Os questionários foram aplicados aos vinte e sete distribuidores associados à Associação dos Distribuidores de Defensivos do Centro-Sul (ADDCS), à transportadora Luft, ao Instituto Nacional de Processamento de Embalagens Vazias (INPEV), ao Instituto Ambiental do Paraná (IAP), à Agência de Defesa Agropecuária do Paraná (ADAPAR), ao Instituto das Águas, à própria ADDCS e a três produtores, considerando um pequeno, um médio e um de grande porte. Na sequência, são apresentados os principais fatores de análise a partir do questionário sociométrico.

\begin{tabular}{|l|l|l|}
\hline Constructo & Definição Constitutiva & Definição Operacional \\
\hline 1. Densidade (conectividade) & $\begin{array}{l}\text { O número de ligações atuais em relação } \\
\text { ao número total de ligações possíveis. }\end{array}$ & $\begin{array}{l}\text { Análise da matriz gerada a partir das } \\
\text { respostas obtidas por meio de } \\
\text { questionário sociométrico. }\end{array}$ \\
\hline 2. Centralidade (degree) & $\begin{array}{l}\text { Define quantos laços o ator possui na } \\
\text { rede ou qual o seu nível de conexão. }\end{array}$ & $\begin{array}{l}\text { Análise do sociograma gerado pelo } \\
\text { software NetDraw e Ucinet. }\end{array}$ \\
\hline 3. Centralidade de acesso (closeness) & $\begin{array}{l}\text { Referente à distância dos outros atores } \\
\text { ou o quão próxima é a ligação em relação } \\
\text { ao conjunto da rede. }\end{array}$ & $\begin{array}{l}\text { Análise do sociograma gerado pelo } \\
\text { software NetDraw e Ucinet. }\end{array}$ \\
\hline $\begin{array}{l}\text { 4. Centralidade de controle } \\
\text { (betweenness) }\end{array}$ & $\begin{array}{l}\text { Estabelece o grau de importância para a a } \\
\text { difusão de informações dentro da rede. }\end{array}$ & $\begin{array}{l}\text { Análise do sociograma gerado pelo } \\
\text { software NetDraw e Ucinet. }\end{array}$ \\
\hline
\end{tabular}

Figura 1. Itens de análise

Fonte: Adaptada de Petterson (2016). 
Os dados coletados a partir dos questionários foram confrontados com os diálogos coletados por meio de entrevistas, a fim de evidenciar as condições de centralidade e densidade representadas na rede em estudo. Foram realizadas entrevistas semiestruturadas, o roteiro possuía 18 questões que nortearam a coleta de dados e foi construído de acordo com o objetivo da pesquisa e as informações destacadas no referencial teórico e também quanto à estrutura e aos relacionamentos. Posteriormente, realizou-se a análise do conteúdo de acordo com as falas de cada um dos entrevistados frente aos eixos norteadores para análise, conforme destacado na introdução.

Foram entrevistados 5 atores que fazem parte da rede vinculados à região centro-sul, destacando aqui seus respectivos órgãos e/ou funções, preservando, no entanto, suas identidades. Foram denominados como entrevistados $A$, $B, C, D, E$, conforme o que se apresenta no Figura 2.

\begin{tabular}{|l|l|l|l|}
\hline \multicolumn{1}{|c|}{ Nome fictício } & \multicolumn{1}{|c|}{ Órgão que representa } & \multicolumn{1}{|c|}{ Escolaridade } & $\begin{array}{l}\text { Frequência de contato com } \\
\text { ADDCS }\end{array}$ \\
\hline Entrevistado A & Gestor ADDCS & Superior & Diária \\
\hline Entrevistado B & Gestor do INPEV & Superior & Diária \\
\hline Entrevistado C & Produtor 1 & Superior & Semestral \\
\hline Entrevistado D & Produtor 2 & Médio & Anual \\
\hline Entrevistado E & Produtor 3 & Médio & Anual \\
\hline
\end{tabular}

Figura 2. Perfil dos entrevistados

Fonte: Dados Primários da pesquisa.

As entrevistas ocorreram nos meses de outubro e novembro de 2017 na cidade de Guarapuava. Foram escolhidos os representantes dos órgãos e das funções que possuem relacionamento com a ADDCS no desenvolvimento de suas atividades. Cada gravação teve uma média de 37,68 minutos. Obteve-se um tempo total de 3 horas e 14 minutos submetidos à transcrição literal das falas para posterior análise de conteúdo como foco nos eixos destacados, como estrutura da rede, práticas de gestão, resultados obtidos, intensidade e influência dos relacionamentos.

\section{ANÁLISE DO CASO}

\subsection{Estrutura da rede no retorno das embalagens de defensivos}

Evidencia-se a formação de rede na relação de vários atores ou diferentes agentes envolvidos em um processo, seguindo a característica inicial de envolvimento de aspectos internos com os externos não exclusivamente dominante por uma empresa. Nesse sentido, observa-se que a relação em redes propõe, de certa forma, aproveitar características do ambiente externo, presentes nas empresas concorrentes e aproximar da própria empresa, a fim de garantir a sobrevivência diante das condições de concorrência (Araújo, 2000).

Impulsionado, inicialmente, pela legislação que estabelece a necessidade de uso adequado dos defensivos agrícolas, e depois por meio da Lei $n^{0} 7.802$, de 11 de julho de 1989 (Brasil, 1989), do Decreto $n^{0} 4.074$, de janeiro de 2002 (Brasil, 2002), dispõe sobre as condições de venda, comercialização, utilização e destino final das embalagens, bem como controle, inspeção e fiscalização de todo processo, em virtude do grau de risco ocasionado pelo uso incorreto de tal produto (Lacerda, 2002).

De acordo com as leis anteriormente citadas, as embalagens de defensivos agrícolas devem retornar à indústria, considerando-se que esse tipo de resíduo sólido contém substâncias químicas que afetam o meio ambiente e a saúde humana (Waichman, 2012).

$\mathrm{Na}$ cidade de Guarapuava-PR, um dos importantes agentes da rede de cooperação no retorno de embalagens é a Associação dos Distribuidores de Defensivos do Centro Sul (ADDCS). Além de ser o maior ponto de coleta das embalagens na região, realiza coleta, triagem e encaminhamento dos materiais à indústria produtora de insumos e às organizações recicladoras do material coletado, além de fazer o trabalho de campo na conscientização dos produtores sobre a importância da devolução das embalagens, considerando os riscos que podem causar à saúde e ao meio ambiente (Ferri et al., 2015). 
Nesse processo de logística reversa das embalagens de defensivos agrícolas, de acordo com Ladeira et al. (2012), inicialmente, tem-se a indústria produtora, que é responsável pela destinação correta dos resíduos de seu produto, ou seja, das embalagens, considerando que, no Brasil, o número de indústrias atuantes na área é superior a cem e que a dificuldade de retorno das embalagens era imensa apenas para cada indústria receber, controlar e destinar para local adequado. Nessa conjuntura, criou-se o Instituto Nacional de Processamento de Embalagens Vazias (INPEV), em 2002. Todo este processo de logística reversa é chamado campo limpo (INPEV, 2017), como pode ser visto na Figura 3.

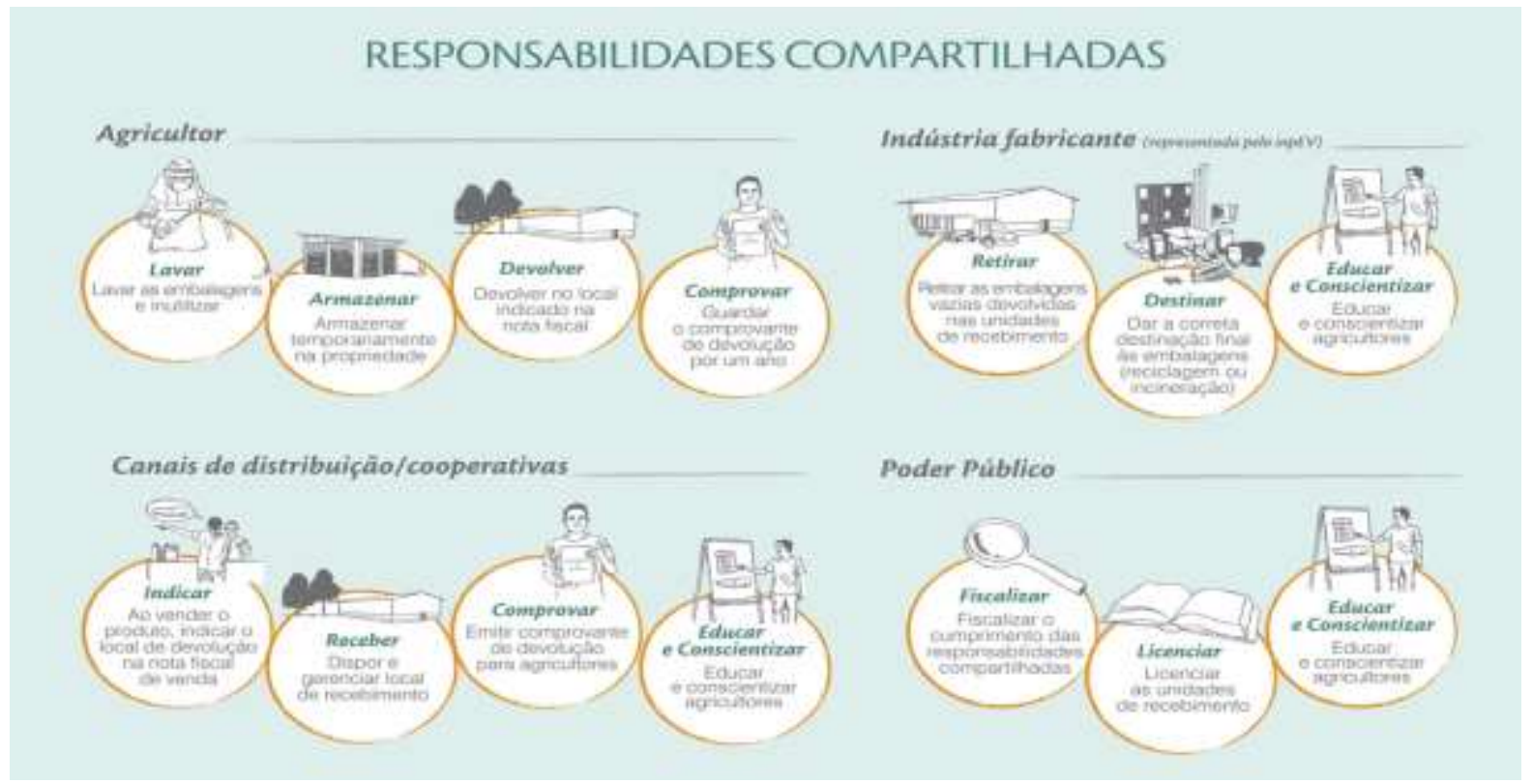

Figura 3. Fluxo do processo de logística reversa das embalagens de defensivos agrícolas. Fonte: Adaptada INPEV (2017).

De acordo com Balestrin e Verschoore (2008), o fluxo desse processo, no sentido de rede de cooperação, compreende uma sequência de agentes interconectados, que buscam a solução para o problema do descarte e do retorno das embalagens. $O$ governo federal e o ministério da agricultura regulamentam e fiscalizam a aquisição e o retorno dessas embalagens. A indústria produtora atua no financiamento desse processo. Os distribuidores ou os fornecedores atuam como vendedores e, também, como postos de coleta desses materiais após sua utilização. O produtor ou consumidor faz uso e entrega do material, além das associações que trabalham diretamente na conscientização, na coleta, na triagem e no direcionamento de todo material (Demajorovic \& Massote, 2017).

Para tanto, cada agente dentro da rede possui papel fundamental no processo de conscientização e retorno das embalagens. Diante disso, nota-se quão é importante o tema em estudo, pois a inter-relação no processo poderá contribuir de modo efetivo nos resultados alcançados.

\subsection{Análise dos resultados}

Com base nos dados coletados, foi possível mapear a rede no processo de logística reversa das embalagens de defensivos agrícolas, bem como compreender a relação de centralidade e densidade dos agentes dessa rede. De acordo com Contractor et al. (2011), cada agente pertencente a uma rede é representado por um ponto dentro de um gráfico, o qual demonstra as inter-relações, cada link representa uma conexão simétrica, ilustrada a partir de linhas e nós, logo um agente localizado no centro é visto, estruturalmente, como mais central. Assim, distingue-se centralidade em três níveis diferentes, descritos como degree (grau), betweeness (intermediação) ou closeness (proximidade) em que, de acordo com Mizruchi (2006, p. 83), "grau se refere ao número de laços diretos entre um e outros agentes de uma rede. A proximidade se refere à medida em que um agente pode alcançar um grande número de outros, com pequeno número de passos. E a intermediação se refere à medida em que um agente cria um caminho singular até outros agentes".

Logo, de acordo com os dados coletados, graficamente a rede de logística reversa de defensivos agrícolas do centro-sul do estado do Paraná é representada na Figura 4. 


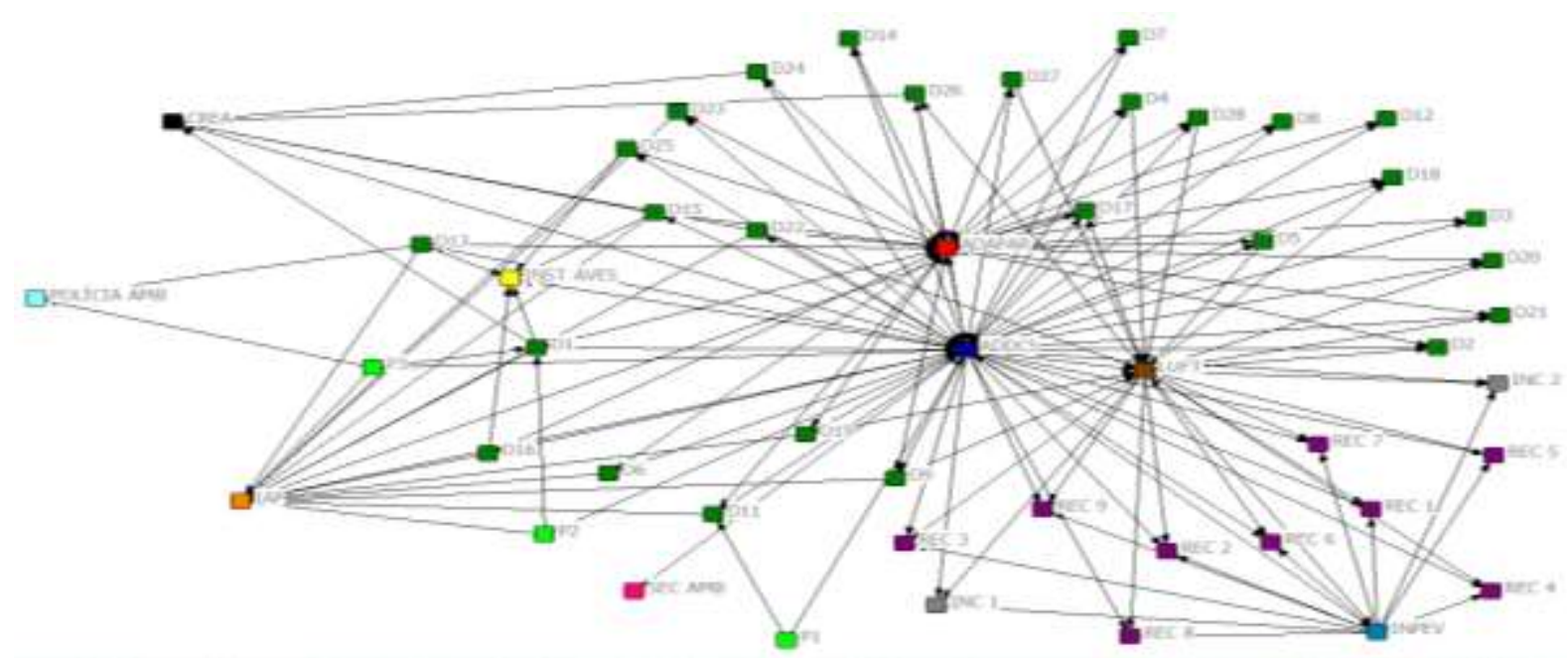

Figura 4. Rede do processo de logística reversa na região centro sul do Paraná Fonte: Representação da rede pelo NetDraw.

Na Figura 4 estão representados os agentes e suas relações, conforme siglas apresentadas na Figura 5.

\begin{tabular}{|l|l|l|}
\hline COR & SIGLA & AGENTE \\
\hline & D1 ao D27 & Distribuidores \\
\hline & INPEV & Instituto Nacional de Processamento de Embalagens Vazias \\
\hline & POLICCIA AMB & Polícia Ambiental \\
\hline & ADDCS & Associação dos Distribuidores Defensivos do Centro Sul \\
\hline & REC1 ao REC9 & Reciclador \\
\hline & LUFT & LUFT Transportadora \\
\hline$\square$ & ADAPAR & Agência de Defesa Agropecuária do Paraná \\
\hline$\square$ & INST AGUAS & Instituto das Águas \\
\hline & IAP & Instituto Ambiental do Paraná \\
\hline & INC1/ INC2/ INC 3 & Incinerador \\
\hline & CREA & Conselho Regional de Engenharia e Agronomia do Paraná \\
\hline & SEC AMB & Secretaria Ambiental \\
\hline & P1/ P2/ P3 & Produtor \\
\hline
\end{tabular}

Figura 5. Legenda atores da rede

Fonte: Dados Ucinet e NetDraw (2017).

Fazem parte da rede todos os agentes citados no quadro de legenda e, no entanto, a ADDCS representa todos os 27 distribuidores citados. Esses estão localizados no município de Guarapuava-PR e região, conforme explica o entrevistado A:

[...] Palmital, tem até em Ivaiporã, a gente vai. Palmital, Pitanga, Laranjal, Santa Maria do Oeste, Pinhão, Candói, as mais distantes seriam Palmital, Cândido de Abreu e Ivaiporã, que são as mais longes daqui. Aí passou dessas cidades já tem uma outra associação. Campo Mourão que daí abrange aquela região lá, no Paraná são treze unidades, que é dividida em regiões.

Ressalta-se, ainda, que toda empresa que trabalha com a comercialização de defensivos agrícolas deve ser vinculada a uma associação de recebimento das embalagens utilizadas, como explica o entrevistado A: "O empresário que quiser entrar nesse mercado de revenda de agroquímicos, ele tem que, obrigatoriamente, se associar numa unidade de recebimento".

Os demais atores que fazem parte da rede possuem como função a fiscalização e as atividades educativas, no sentido de fazer com que o produtor compreenda a importância desse processo, são eles: Polícia Ambiental, Secretaria do Meio Ambiente, Instituto das Águas, Instituto Ambiental do Paraná e Agência de Defesa Agropecuária do Paraná 
(ADAPAR). Além de recicladoras, incineradoras, transportadora e produtor, independente do porte e da quantidade consumida, fazem parte da rede, e o INPEV.

O INPEV é o financiador de mais de $70 \%$ desse processo, os outros 30\% geralmente os associados da ADDCS devem financiar. O INPEV também é a figura inicial, pois representa as 116 indústrias que atuam no mercado brasileiro, com produção e comercialização dos defensivos, impulsionado por uma lei nacional que obriga a realizar a coleta deste material, a fim de evitar uma série de problemas ambientais e sociais. Ele se tornou o mentor e o responsável pela continuidade das atividades relacionadas ao processo de recolhimento e reciclagem das embalagens. Questionou-se quem eram os possíveis parceiros da associação e como contribuem para suas atividades, o entrevistado $A$ argumentou: "[...] O órgão parceiro é o INPEV, que é a associação da indústria fabricante, o INPEV é Instituto Nacional de Processamento de Embalagens Vazias". O entrevistado B destacou que: "Ele é o co-gerenciador das unidades de recebimento que, no Brasil, em questões de logística de padronização de operações e financeiramente também. Ele paga $70 \%$ do deficit de cada unidade e todas elas são deficitárias". 0 entrevistado A argumenta: "Nenhuma das associações visa lucro, mas geralmente para fechar a conta, eles arcam com 30\% dos custos, para complementar o valor subsidiado pelo INPEV".

Logo, buscou-se compreender quão densas são as relações entre os agentes, ou seja, o número de relações e conectividade, se alta ou baixa.

Tabela 1.

Grau de densidade

\begin{tabular}{lllll}
\hline \multicolumn{2}{l}{ DENSIDADE / VALOR MATRIZ MÉDIO } & & & \\
\hline Density & No. of Ties & Std Dev & Avg Degree & Alpha \\
\hline 0.081 & 207 & 0.273 & 4.059 & 0.818 \\
\hline
\end{tabular}

Fonte: Dados gerados pelo Ucinet.

Assim, há um total de 51 nós e 207 relações existentes de 2.550 possíveis, o que demonstra uma densidade de 0,081 ou $8,1 \%$ de relações possíveis dentro da rede. Sobretudo no caso em estudo, o total de conexões se faz importante quando se trata da disseminação das informações referentes aos procedimentos que devem ser adotados, bem como 0 fortalecimento sobre a importância da entrega das embalagens de modo correto no prazo preestabelecido, mesmo que 0 contato principal dos produtores seja a ADDCS, o máximo de relação e conexões com os diversos atores pertencentes à rede favorece a institucionalização dos processos. Sendo que, de acordo com Sacomano Neto (2004), "quanto maior a interconexão, maior a densidade [...] facilita o fluxo de informações e recursos. Sistema fechado de confiança e normas compartilhadas. Facilita a atribuição de sanções".

O grau de centralidade (Centrality Degree) é o número de atores aos quais um ator está, diretamente, ligado, o qual se divide em grau de entrada (soma das interações dos atores da rede com um ator específico) e saída (soma de interação do ator para com os outros atores da rede) (Mizruchi, 2006).

\section{Tabela 2.}

Medidas de grau de centralidade

\begin{tabular}{ccccccccc}
\hline & Outdeg & Indeg & Soma & nOutdeg & nlndeg & Betweenness & nBetweenness \\
\hline LUFT & 19.000 & 13.000 & 32 & 0.380 & 0.260 & 89.667 & 3.660 \\
\hline ADDCS & 46.000 & 34.000 & 80 & 0.920 & 0.680 & 958.798 & 39.135 \\
\hline RECICLADORA 1 & 0.000 & 3.000 & 3 & 0.000 & 0.060 & 0.000 & 0.000 \\
\hline RECICLADORA 2 & 0.000 & 3.000 & 3 & 0.000 & 0.060 & 0.000 & 0.000 \\
\hline RECICLADORA 3 & 0.000 & 3.000 & 3 & 0.000 & 0.060 & 0.000 & 0.000 \\
\hline RECICLADORA 4 & 0.000 & 3.000 & 3 & 0.000 & 0.060 & 0.000 & 0.000 \\
\hline RECICLADORA 5 & 0.000 & 3.000 & 3 & 0.000 & 0.060 & 0.000 & 0.000 \\
\hline RECICLADORA 6 & 0.000 & 3.000 & 3 & 0.000 & 0.060 & 0.000 & 0.000 \\
\hline RECICLADORA 7 & 0.000 & 3.000 & 3 & 0.000 & 0.060 & 0.000 & 0.000 \\
\hline RECICLADORA 8 & 0.000 & 3.000 & 3 & 0.000 & 0.060 & 0.000 & 0.000 \\
\hline
\end{tabular}

(Continua) 


\begin{tabular}{|c|c|c|c|c|c|c|c|}
\hline & Outdeg & Indeg & Soma & nOutdeg & nlndeg & Betweenness & $\begin{array}{r}\text { (Conclusão } \\
\text { nBetweenness }\end{array}$ \\
\hline RECICLADORA 9 & 0.000 & 3.000 & 3 & 0.000 & 0.060 & 0.000 & 0.000 \\
\hline INCINERADORA 1 & 0.000 & 3.000 & 3 & 0.000 & 0.060 & 0.000 & 0.000 \\
\hline INCINERADORA 2 & 0.000 & 3.000 & 3 & 0.000 & 0.060 & 0.000 & 0.000 \\
\hline ADAPAR & 29.000 & 29.000 & 58 & 0.580 & 0.580 & 381.167 & 15.558 \\
\hline DISTRIBUIDOR 1 & 5.000 & 4.000 & 9 & 0.100 & 0.080 & 3.405 & 0.139 \\
\hline DISTRIBUIDOR 2 & 3.000 & 3.000 & 6 & 0.060 & 0.060 & 0.226 & 0.009 \\
\hline DISTRIBUIDOR 3 & 2.000 & 2.000 & 4 & 0.040 & 0.040 & 0.000 & 0.000 \\
\hline DISTRIBUIDOR 4 & 3.000 & 2.000 & 5 & 0.060 & 0.040 & 0.083 & 0.003 \\
\hline DISTRIBUIDOR 5 & 3.000 & 2.000 & 5 & 0.060 & 0.040 & 0.083 & 0.003 \\
\hline DISTRIBUIDOR 6 & 3.000 & 2.000 & 5 & 0.060 & 0.040 & 0.071 & 0.003 \\
\hline DISTRIBUIDOR 7 & 2.000 & 2.000 & 4 & 0.040 & 0.040 & 0.000 & 0.000 \\
\hline DISTRIBUIDOR 8 & 2.000 & 2.000 & 4 & 0.040 & 0.040 & 0.000 & 0.000 \\
\hline DISTRIBUIDOR 9 & 4.000 & 2.000 & 6 & 0.080 & 0.040 & 0.155 & 0.006 \\
\hline DISTRIBUIDOR 10 & 3.000 & 2.000 & 5 & 0.060 & 0.040 & 0.071 & 0.003 \\
\hline DISTRIBUIDOR 11 & 3.000 & 3.000 & 6 & 0.060 & 0.060 & 1.071 & 0.044 \\
\hline DISTRIBUIDOR 12 & 2.000 & 2.000 & 4 & 0.040 & 0.040 & 0.000 & 0.000 \\
\hline DISTRIBUIDOR 13 & 5.000 & 2.000 & 7 & 0.100 & 0.040 & 33.238 & 1.357 \\
\hline DISTRIBUIDOR 14 & 2.000 & 2.000 & 4 & 0.040 & 0.040 & 0.000 & 0.000 \\
\hline DISTRIBUIDOR 15 & 5.000 & 2.000 & 7 & 0.100 & 0.040 & 0.405 & 0.017 \\
\hline DISTRIBUIDOR 16 & 4.000 & 2.000 & 6 & 0.080 & 0.040 & 0.238 & 0.010 \\
\hline DISTRIBUIDOR 17 & 4.000 & 3.000 & 7 & 0.080 & 0.060 & 0.798 & 0.033 \\
\hline DISTRIBUIDOR 18 & 3.000 & 3.000 & 6 & 0.060 & 0.060 & 0.226 & 0.009 \\
\hline DISTRIBUIDOR 19 & 4.000 & 2.000 & 6 & 0.080 & 0.040 & 0.155 & 0.006 \\
\hline DISTRIBUIDOR 20 & 2.000 & 3.000 & 5 & 0.040 & 0.060 & 0.143 & 0.006 \\
\hline DISTRIBUIDOR 21 & 3.000 & 3.000 & 6 & 0.060 & 0.060 & 0.226 & 0.009 \\
\hline DISTRIBUIDOR 22 & 5.000 & 2.000 & 7 & 0.100 & 0.040 & 0.321 & 0.013 \\
\hline DISTRIBUIDOR 23 & 3.000 & 2.000 & 5 & 0.060 & 0.040 & 0.071 & 0.003 \\
\hline DISTRIBUIDOR 24 & 3.000 & 2.000 & 5 & 0.060 & 0.040 & 0.167 & 0.007 \\
\hline DISTRIBUIDOR 25 & 4.000 & 2.000 & 6 & 0.080 & 0.040 & 0.238 & 0.010 \\
\hline DISTRIBUIDOR 26 & 3.000 & 3.000 & 6 & 0.060 & 0.060 & 0.810 & 0.033 \\
\hline DISTRIBUIDOR 27 & 3.000 & 2.000 & 5 & 0.060 & 0.040 & 0.083 & 0.003 \\
\hline DISTRIBUIDOR 28 & 3.000 & 2.000 & 5 & 0.060 & 0.040 & 0.083 & 0.003 \\
\hline IAP & 0.000 & 16.000 & 16 & 0.000 & 0.320 & 0.000 & 0.000 \\
\hline CREA & 0.000 & 6.000 & 6 & 0.000 & 0.120 & 0.000 & 0.000 \\
\hline INPEV & 13.000 & 2.000 & 15 & 0.260 & 0.040 & 0.000 & 0.000 \\
\hline INST ÁGUAS & 0.000 & 6.000 & 6 & 0.000 & 0.120 & 0.000 & 0.000 \\
\hline SEC AMB & 0.000 & 1.000 & 1 & 0.000 & 0.020 & 0.000 & 0.000 \\
\hline \multirow[t]{2}{*}{ POLÍCIA AMB } & 0.000 & 2.000 & 2 & 0.000 & 0.040 & 0.000 & 0.000 \\
\hline & 0.8556 & 0.6108 & & & & & \\
\hline
\end{tabular}

Fonte: Dados Ucinet (2017).

Analisando a medida de centralidade de grau, foram citados 51 agentes, porém se nota que 5 deles foram mais citados, sendo: Luft, ADDCS, ADAPAR, IAP E INPEV, ou seja, transportadora, associação dos distribuidores, órgãos fiscalizadores e INPEV. O destaque fica para ADDCS, com 80 conexões, representado por um percentual de outdeg 0,920 e indeg 0,680 , em que se que pode inferir que as atividades prestadas pela associação possuem impacto no processo e nas relações com demais agentes. Na sequência, ADAPAR, com 58 conexões; depois, a transportadora Luft, com 32 conexões, considerando que a maior parte dos produtores fazem a entrega uma vez no ano das embalagens utilizadas; IAP, com 16 conexões; e INPEV, com 15 e um percentual de outdeg 0,260 e INPEV 0.040. 


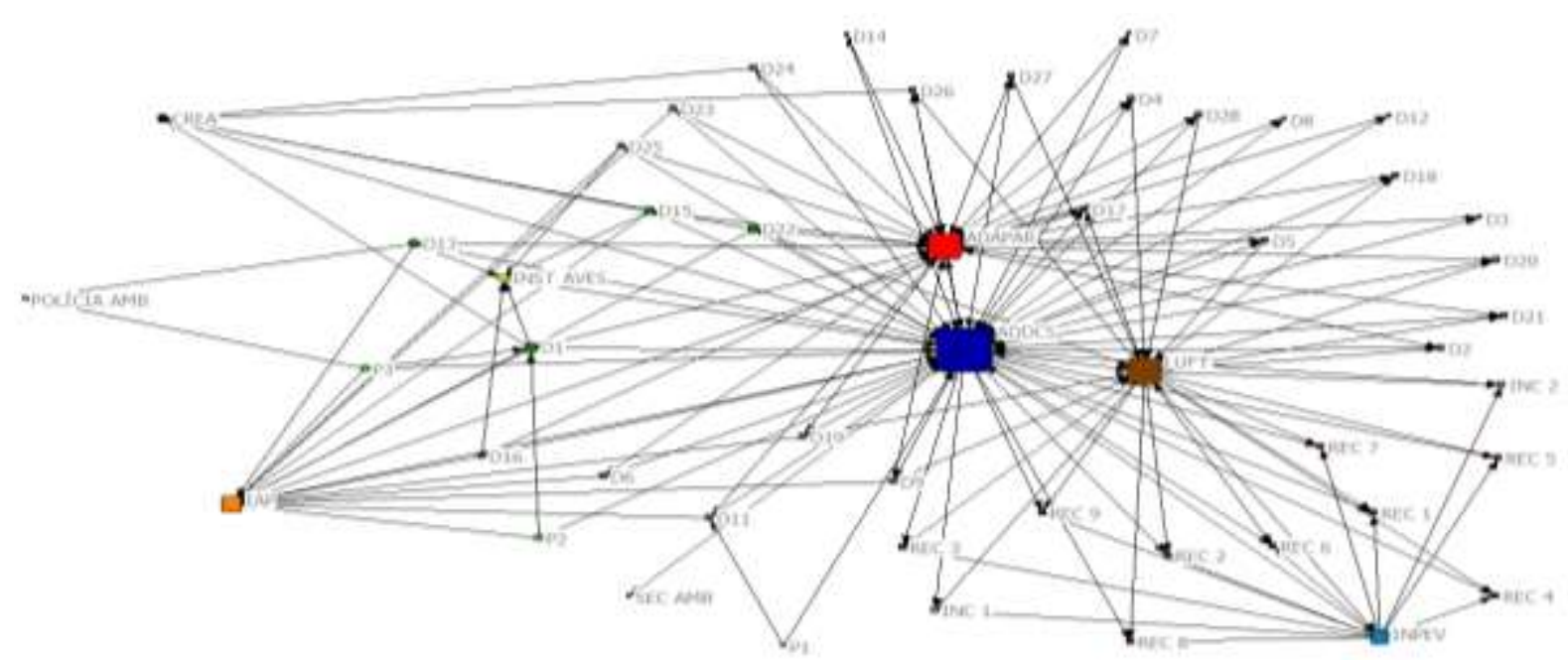

Figura 6. Grau de centralidade (Degree)

Fonte: Dados NetDraw (2017).

De acordo com a Figura 6, pode-se perceber, graficamente, os resultados em relação ao grau de centralidade, ou seja, os atores da rede que mais possuem destaque, conforme já comentado com base nos dados demonstrados na Tabela 1. Desse modo, ressalta-se que os atores centrais possuem um maior nível de relacionamento, no que tange aos aspectos relacionados ao processo de retorno das embalagens de defensivos agrícolas. Em entrevista realizada com representante da ADDCS, sobre se a associação mantém contato direto com o produtor ou apenas no momento que ele vem fazer a entrega das embalagens, o entrevistado $C$ menciona que "Temos um contato maior com ADDCS no momento que vem fazer a entrega só das embalagens e eles emitem comprovante e dão baixa na nota fiscal". Já o entrevistado $E$ argumenta que "o contato maior do produtor é com a revenda que ele escolheu, que é a associada, então seu contato maior é com a revenda e conosco é só no momento da entrega mesmo ou quando ele pede pra gente ir até lá ou quando a gente detecta problema e vai até lá então".

Com base neste fragmento, entende-se que, no que diz respeito ao funcionamento do processo de logística reversa das embalagens, o contato é com a associação. Apenas em relação ao produto, seu contato é maior e mais frequente com o próprio distribuidor, porém quando os atores envolvidos na rede responderam a entrevista de associação sociométrica, ficou evidente o contato com a associação no processo de devolução.

Além de tratar o grau de centralidade, avalia-se também a capacidade de determinado agente atuar como ponte entre as relações da rede, ou seja, a capacidade de intermediar a comunicação entre dois nós (Freeman, 1979).

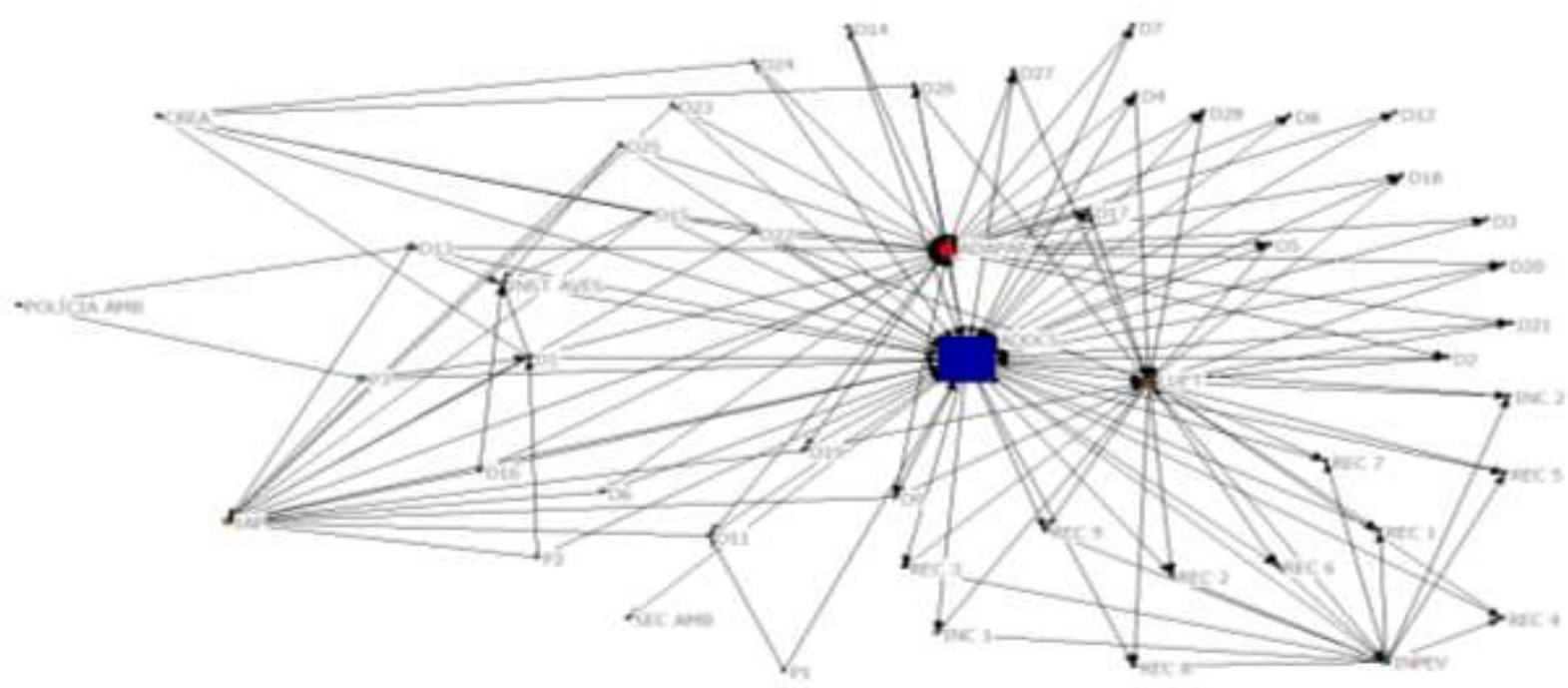

Figura 7. Grau de Intermediação (Betweenss)

Fonte: Dados NetDraw (2017). 
Assim, das empresas com destaque na intermediação entre diferentes agentes, considerando as 51 citadas, apenas 3 possuem destaque, ADDCS, com mais de 39\% no quesito intermediação das relações entre distribuidores e produtores, bem como entre produtores, recicladores e incineradores, por exemplo; Luft em uma porcentagem menor, mas se caracteriza como facilitadora no sentido de auxiliar na entrega de materiais, tanto de distribuidores e produtores para associação, bem como para com incineradoras e recicladoras; por fim, ADAPAR, que como órgão fiscalizador, foca a relação produtor e associação de recebimento das embalagens.

Fragmento na resposta que o entrevistado A menciona relação com produtor, argumentando que "sempre a gente está orientando, educando, ou mesmo fora desses encontros programados normalmente como o produtor vem aqui entregar e a gente detecta algum problema, a gente orienta ele na hora é um trabalho constante para que ele faça a parte dele". O entrevistado B complementa: "A lei dividiu as responsabilidades produtor, revendedor e indústria, cada um tem uma obrigação".

Em suma, o índice de centralização de intermediação da rede é igual a 38,72\%, isto é, 3 empresas, com maior potencial de intermediação, destacadas como elos mais fortes entre outros atores. Assim, ADDCS destaca-se por demonstrar maior grau de inter-relação.

Entre os 51 nós da rede de interação, quatro deles possuem maior grau de proximidade. Desses, a ADDCS conta com maior representatividade em aspectos Out Close dela para com os demais agentes, em virtude das relações que buscam maior capacidade e otimização nos processos, as quais afetam a rede e a perspectiva dos seus resultados. Nesse caso, ressalta-se a importância da figura da associação dentro da rede, pois a partir de suas atividades, as ações dos demais atores permitem o alcance de melhores resultados. Sobre isso, o entrevistado B menciona que "as atribuições são receber as embalagens vazias de agroquímicos, orientar o produtor ou os produtores e também atuar na educação ambiental junto às escolas e com os produtores, palestras, oficinas, workshops, enfim, educação ambiental e conscientização, também faz parte do nosso trabalho". No entanto, o entrevistado D afirma que "a atuação da ADDCS na região ainda é falha, eles não vão a campo, a gente vê apenas em eventos promovidos pelo sindicato rural ou associação dos produtores, mas eles vir nas propriedades ou manter um contato com produtores, nunca vi". Em contrapartida, 0 entrevistado A diz: "Pode existir a possibilidade de algum evento ou fazer aqui uma palestra ou evento na associação e posso buscar patrocínio nas revendas ou em alguma indústria, mas é muito difícil conseguir, nem vou atrás mais, porque eles já pagam, a indústria já faz um aporte".

A associação possui diferentes relações com os agentes que pertencem à rede, com diferentes frequências de contato, por exemplo, o produtor, seu interesse se restringe ao recebimento das embalagens, já o INPEV direciona toda sua forma de trabalho, além de financiar grande parte de suas atividades, conforme argumenta o entrevistado A: "Somos uma entidade sem fins lucrativos, de direito privado, tem o presidente, tem o tesoureiro, tem o administrador, técnico, responsável técnico, então, tem um corpo jurídico administrativo como uma empresa qualquer, não tá isenta de nenhum imposto de nenhuma taxa". O entrevistado B diz que a ADDCS "não comercializa nada, não compra e não vende produtos, só cumpre a lei de receber as embalagens e dar o destino correto pra elas". O entrevistado A reforça que "a fiscalização não contribui, ela fiscaliza, faz o trabalho deles né, eles não contribuem, quem é parceiro é o INPEV".

0 propósito do estudo ao investigar o grau de centralidade e densidade dentro da rede revela que, realmente, existem relações interpessoais e que estas geram maior capacidade no alcance dos resultados propostos no processo de logística reversa. Sobre isso, o entrevistado A comenta que: "Aqui em Guarapuava chega a 97\% (recolhimento de embalagens do total comercializado) em termos de Brasil dá $95 \%$, o país que chega mais perto da gente que é a França tá em $60 \%$, o Estados Unidos tá em $33 \%$ de devolução". Já o entrevistado B conta que "teve um pessoal da Argentina na unidade de Ponta Grossa. Eles vieram saber por que que funciona no Brasil e como que funciona, eles não entendem 0 Brasil com dimensões continentais com todos os problemas que tem e esse sistema funcionar bem". O entrevistado $\mathrm{E}$ complementa que "a vantagem a maior vantagem é para a sociedade, pro meio ambiente, tá protegendo o meio ambiente, protegendo a saúde das pessoas, retirando um material que é poluente e perigoso, que é material tóxico". Para entrevistado C, "a maioria, tá lavando, tá separando, tá entregando, se não fosse pelo produtor o sistema ficaria sem sentido, por isso que a lei foi muito bem feita, as responsabilidades foram compartilhadas, cada um tem que cumprir sua parte. E todo mundo ganha, então eu acho o benefício é pra sociedade como um todo".

Os dados expostos pelo entrevistado demonstram que, apesar de alguns problemas, os resultados já alcançados são positivos. Todavia, o entrevistado A menciona alguns problemas: "Nós detectamos [...] não seria uma dificuldade, mas é um problema, que é pequeno produtor. Ele tem uma ideia errada, que ele não precisa entregar a embalagem que ele usa pouco, e então não vai dar problema e dá a lei não faz distinção entre uma embalagem e mil embalagens". 
De acordo com entrevistado, a maior parte das embalagens que não são devidamente entregues são dos pequenos produtores, que consomem poucas quantidades e não reconhecem a necessidade de entrega. Assim 0 entrevistado A destaca:

A gente sabe que tá atacando esse problema com reuniões, palestras, a gente reúne, aqui em Guarapuava tem a COMURB, que é o Conselho Municipal dos Produtores Rurais, pequeno produtor rural, e a gente já conseguiu conscientizar muitas comunidades aí, da importância dessa devolução, então acho que hoje um problema seria esse é [...] porque qual que é nosso objetivo, nossa missão é chegar no 100\% né, mas a gente já sabe onde que tá o problema e tá atacando esse problema. E outra coisa seria, talvez, as distâncias de recicladoras, de incineradores, tudo fora do estado a maioria, custo da logística muito alto, isso seria o maior problema nosso, seria essa distância.

No entanto, apesar da fala do entrevistado, pode-se notar, a partir dos dados tabulados por meio do software Ucinet, que a interconexão entre os agentes ainda é baixa, o que caracteriza como uma rede interoganizacional difusa, pois, mesmo com os intercâmbios realizados, o percentual apresentado não caracteriza um alto nível de proximidade. Dessa forma, mesmo apresentando uma característica difusa, a rede ainda está em desenvolvimento, considerando a volatilidade no mercado, nos níveis de produção, a obrigatoriedade de devolução, os padrões exigidos, como a tríplice lavagem. Em suma, as relações ainda possuem características de subjetividade entre os atores, fortemente influenciados pela obrigatoriedade de devolução das embalagens, do que uma relação de cooperação para atingir com maior eficiência os objetivos e os resultados.

\section{CONSIDERAÇÕES FINAIS}

Por meio desse estudo, buscou-se identificar o grau de centralidade e densidade no processo de logística reversa de embalagens de defensivos agrícolas, e pôde-se notar a existência de uma rede interorganizacional, formada por normas e valores. Algo que fica muito evidente no estudo quando se trata de aspectos de densidade e centralidade. Com base nos dados, permite-se dizer que há uma relação interorganizacional, mas os resultados apontam ainda uma rede com características difusas, ou seja, a relação à baixa ou à inexistência de contato entre alguns atores, podem ser fatores que ainda venham a restringir 0 alcance de melhores resultados, sendo que muitas vezes as ações dos agentes são induzidas por possíveis sanções que possam sofrer em virtude da lei e não realmente com foco na busca de melhores resultados, no que tange à entrega das embalagens no prazo correto, com devida lavagem e perfuração, minimização do comércio clandestino de produtos falsificados que não entram nas estatísticas das embalagens a serem devolvidas, entre outros fatores que influenciam a interconexão dos atores.

A rede na região centro sul do Paraná é formada por 27 distribuidores, que são associados da Associação de Distribuidores da região, mantida pelo Instituto Nacional de Processamento de Embalagens vazias, além de contar com atuação de órgãos fiscalizadores, como ADAPAR, IAP, Instituto das Águas, entre outros, também envolve as recicladoras, as incineradoras e os produtores.

Assim, o estudo quanto à estrutura, ao mapeamento da rede e às propriedades quanto à centralidade e à densidade, permitiu o entendimento dos conceitos que envolvem a rede. Os dados coletados foram mensurados utilizando software específico e permitiram a análise quanto à estrutura local da rede, considerando que a análise foi de uma parte ou fragmento da rede, que este processo ocorre a nível nacional e o foco do estudo está na região centro sul do Paraná.

O objetivo do estudo foi atendido, a análise apresentou os principais resultados encontrados nas entrevistas realizadas, em que foram identificados aspectos importantes para direcionamentos futuros, no que diz respeito à ampliação de interconexões, às normas, ao acesso a recursos, às informações e à confiança.

Destaca-se que, por meio do modelo adotado, pode-se identificar na coleta de dados quem eram os atores citados, bem como a frequência, o motivo e a importância de contato para cada um dos atores que foi destacado pelos respondentes. A partir destes dados, foi possível construir a matriz e, por consequência, a rede e suas conexões, com apoio dos softwares NetDraw e Ucinet, compreendendo os atores centrais, aqueles com maior destaque. Com relação à densidade, vale ressaltar que o percentual alcançado de 8,1\% traduz a necessidade de desenvolver ações que facilitem o contato e as trocas na rede, a fim de manter-se ativa com alcance de bons resultados. De certo modo, os resultados ainda não totalmente satisfatórios podem ser em decorrência do caráter de obrigatoriedade e não pela apropriação racional da importância de tal processo e também pelas características de mercado clandestino de produtos falsificados, que reduzem o potencial do programa. 
Sugere-se, ainda, o desenvolvimento de novos estudos, que busquem identificar outras percepções dentro da rede, ou ainda que tenham como foco outras regiões, ressaltando a amplitude de estudo na área que venham a contribuir com a interconexão e com os relacionamentos estabelecidos na rede, com intuito de alcançar melhores resultados. Também se ressalta que, para obter um novo modelo QAS e novos resultados em relação à rede em estudo, faz-se necessário ampliar a coleta de dados para outras regiões, a fim de identificar os resultados alcançados a partir dos relacionamentos, dos contatos e dos elos criados.

\section{REFERÊNCIAS}

Balestrin, A., Verschoore, J. R., \& Reyes Junior, E. (2010, Mai./Jun.). O Campo de Estudo sobre Redes de Cooperação Interorganizacional no Brasil. RAC, Curitiba, 14(3), 458-477.

Albagli, S., \& Brito, J. (2003). Glossário de Arranjos e Sistemas Produtivos e Inovativos locais. In H. M. M. Cassiolato, \& J. E. RedeSist (Org.). Projeto Arranjos produtivos locais: uma nova estratégia de ação para o Sebrae. Coordenação geral: Lastres,

Araújo, L. (2000). As relações inter-organizacionais. In S. B. Rodrigues, \& M. P. Cunha. Estudos organizacionais: novas perspectivas na administração de empresas, um coletânea luso-brasileira (pp. 500-523). São Paulo: Iglu,

Balestrin, A., \& Verchoore, J. R. (2008). Redes de cooperação empresarial: estratégias de gestão na nova economia. Porto Alegre: Bookman.

Brasil. Decreto $n^{0}$ 4.074, de 04 de janeiro de 2002. Regulamenta a Lei $n^{0} 7.802$, de 11 de julho de 1989. Diário Oficial [da] República Federativa do Brasil. Brasília, DF.

Brasil. Lei $n^{\circ} 7.802$, de 11 de julho de 1989. Dispõe sobre a pesquisa, a experimentação, a produção, a embalagem e rotulagem, o transporte, o armazenamento, a comercialização, a propaganda comercial, a utilização, a importação, a exportação, o destino final dos resíduos e embalagens, o registro, a classificação, o controle, a inspeção e a fiscalização de agrotóxicos, seus componentes e afins, e dá outras providências. Diário Oficial [da] República Federativa do Brasil. Brasília, DF.

Britto, J. (2002). Cooperação interindustrial e redes de empresas. In D. Kupfer, \& L. Hasenclever (Ed.). Economia Industrial (vol. 1, pp. 345-388). Rio de Janeiro: Editora Campus.

Contractor, N., Monge, P., \& Leonardi, P. (2011). Multidimensional networks and the dynamics of socio- materiality: Bringing technology inside the network. International Journal of Communication, 5, 682-720.

Cooper, D. R., \& Schindler, P. S. (2011). Métodos de Pesquisa em Administração (10. ed.). Tradução luri Duquia Abreu. Porto Alegre: Bookman.

Creswell, J. W. (2010). Projeto de pesquisa: métodos qualitativo, quantitativo e misto (3. ed.). Porto Alegre: Artmed/Bookman.

Demajorovic J., Caires, E. F., Gonçalves, L. N. S., \& Silva, M. J. C. (2014). Integrando empresas e cooperativas de catadores em fluxos reversos de resíduos sólidos pós-consumo: o caso Vira-Lata. Cad. EBAPE.BR, 12.

Demajorovic, J., \& Massote, B. (2017, Set.). Acordo setorial de embalagem: avaliação à luz da responsabilidade estendida do produtor. Rev. adm. empresas, 57(5), 470-482.

Farina, M., Silva, R., Silva Filho, J., Silveira, M., Ozaki, M., \& Benevides, G. (2013, abr./jun.). Uma investigação da centralidade e da densidade de uma rede de empresas que atuam na realização de festas e de casamentos. Revista Alcance - Eletrônica, 20(02), 170-185. 
Ferri, G. L., Chaves, G. L. D., \& Ribeiro, G. M. (2015). Análise e localização de centros de armazenamento e triagem de resíduos sólidos urbanos para a rede de logística reversa: um estudo de caso no município de São Mateus, ES. Production, 25(1), 27-42.

Freeman, L. C. (1979). Centrality in social networks: I. Conceptual clarification. Social Networks, 1(2), 215-239.

Gnyawali, D. R., \& Madhavan, R. (2001, jul.). Cooperative networks and competitive dynamics: a structural embeddedness perspective. Academy of Management Review, 26(3), 431-445.

Goldsby, T. J., \& Closs, D J. (2000). Using activity-based costing to reengineer the reverse logistics channel. International Journal of Physical Distribution \& Logistics Management, 30(6), 500-514

Hanneman, R. A., \& Riddle M. (2011). Introduction to social network methods. Riverside, CA: University of California, Riverside.

Inpev. (2017). Instituto Nacional de Processamento de Embalagens Vazias. Recuperado em 20 mai, 2017, de http://www.inpev.org.br/sistema-campo-limpo/legislacao.

Lacerda, L. (2002). Logística Reversa - Uma Visão sobre os Conceitos Básicos e as Práticas Operacionais Centro de Estudos em Logística, Rio de Janeiro: COPPEAD/UFRJ.

Ladeira, W. J., Maehler, A. E., \& Nascimento, L. F. M. (2012, Mar.). Logística reversa de defensivos agrícolas: fatores que influenciam na consciência ambiental de agricultores gaúchos e mineiros. Rev. Econ. Sociol. Rural, 50(1), 157174.

Marteleto, R. M. (2010, jan/dez.). Redes sociais, mediação e apropriação de informação: situando campo, objetos e conceitos na pesquisa em ciência da informação. Tendências da Pesquisa Brasileira em Ciência da Informação. Brasília, 3(1), .27-46.

Masquieto, C. D., Sacomano Neto, M., \& Giuliani, A. C. (2011). Centralidade e densidade em Redes de empresas: um estudo no arranjo produtivo local do álcool. RAl - Revista de Administração e Inovação, 8(1), 122-147.

Mizruchi, S. M. (2006, Jul./Set.). Análise de redes sociais: avanços recentes e controvérsias atuais. RAE, 46(3), 72-86

Nohria, N. (1992). Is a network perspective a useful way of studying organizations? In N. Nohria, \& R. G. Eccles. Networks an organizations: structure, form and action (pp. 1-22). Boston: Harvard Business School Press, Massachusetts.

Oliver, C. (1990). Determinants of interorganizational relationships: integration and future directions. Academy of Management Review, 15(12), 241-265.

Petterson, A. R. (2016). Redes de cooperação interorganizacional e o papel das entidades de apoio: estudo de caso da feira do produtor de Guarapuava. Dissertação de Mestrado em Administração, Universidade Estadual do CentroOeste, Guarapuava.

Rodrigues, L. C., Maccari, E. A., \& Riscarolli, J. (2007). Arquitetura e competição em redes interorganizacion- ais. Revista de Gestão da Tecnologia e Sistemas de Informação, 4(2), 175-196.

Sacomano Neto, M. (2004). Morfologia, propriedades e posicionamentos das redes: contribuições às análises interfirmas. Anais do SIMPEP, Bauru, SP, Brasil, 11.

Tichy, N. M., Tushman, M. L., \& Fombrun, C. (1979, out.). Social Network Analysis for Organizations. Academy of Management Review, 4(4), 507-519. 
Waichman, A. V. (2017, Jan./Jun.). A problemática do uso de agrotóxicos no Brasil: a necessidade de construção de uma visão compartilhada por todos os atores sociais. Revista Brasileira de Saúde Ocupacional, 37(125), São Paulo. Recuperado em 05 dez., de http://www.scielo.br/scielo.php?script=sci_arttext\&pid=S0303-76572012000100007.

Wasserman, S., \& Faust, K. (1999). Social Network Analysis: methods and applications (4. ed.). Cambridge: Cambridge University Press.

Yin, R. K. (2015). Estudo de Caso: Planejamento e Métodos. Porto Alegre, RS: Bookman Editora Ltda. 